\title{
An Analysis of the Discourse Institutionalism of News Rent-seeking Governance Policy*
}

\author{
$\mathrm{Ke} \mathrm{Li}$ \\ Communication University of Zhejiang \\ Hangzhou, China 310018
}

\begin{abstract}
In the perspective of discourse institutionalism, the change of news rent-seeking governance policy is a discourse interaction process between different policy subjects. With the development of democratization and new media, the discourse expressions of experts and the public in the change of news rentseeking governance policy has become increasingly important, which has enhanced the scientific and systematic nature of policy change. However, in the change of news rent-seeking governance policy, the problem of unequal status, multi-headed governance, and low policy effectiveness cannot be ignored. To promote the optimization of news rent-seeking governance policy, it is necessary to establish a multi-dimensional governance structure, form a multi-layered collaborative policy system, and adopt a variety of policy enforcement measures.
\end{abstract}

Keywords—news rent-seeking; policy change; institutionalism

\section{INTRODUCTION}

The 40 years of reform and opening up have brought earthshaking changes in China's economy and society. China's news media industry has stepped toward marketization, industrialization, and scale in the tide of reform and opening up step by step, and has become an indispensable force in the national economy and society. The reform of the media system in China has prompted the news media transformed from a purely news propaganda agency which perform a single news propaganda mission, to the dual roles of news propaganda agencies and market subject, and during the process due to operational pressures and institutional flaws lead to the abuse of news propaganda power and then breed news rent-seeking. The term news rent-seeking comes from the concept of power rent-seeking in economics and politics, "it refers to a nonproductive activity that the press or journalists use news reporting power, public opinion power, and media communication power to transfer wealth distribution, and seek improper interests for groups or individuals and damage the interests of other social entities [1]".The concrete expression include "Dark-box advertisement", "Burring the boundaries of news and advertising", "News involved in business planning activities", "News extortion", "News broker", "News roles and business roles mixed", "Bribe news" and other forms [2]. News rent-seeking has seriously affected the credibility of the news media and hurt economic and social development. The party and government have continued to strengthen their

*This article is the research result of the National Social Science Fund "A study of CPC Party News Policy Change during the 100 years of establishment (17BXW001)". governance.

The current research on news rent-seeking mainly includes the causes, hazards, and governance measures. With regard to the causes of news rent-seeking, Zhang Zhian and $\mathrm{Wu}$ Jianming believe it is caused by the institutional nature of China's media dual-track operation, government and enterprises are not separated and property rights are unclear, and their governance needs to "improve the corporate governance structure of the media and strengthen internal media supervision". [3] Chen Weixing and Yu Guiquan compare Chinese and Russian media rent-seeking issue from the perspective of historical institutionalism. They believe the root cause of China's media rent-seeking is the dual-track policy loophole of "public institutions and enterprise management", and is the continuation and dissimilation of the news media monopoly right formed by the news media under the traditional bureaucracy management system. [4]Huang Hongzhen believes that the regulatory gap and the mixture of supervision function caused by poor management in new publicity area are also the important reason for news rentseeking. [5] For the harm of news rent-seeking, Zheng Baowei believes that "news extortion is a kind of activity which violate professional ethics and serious violations of law and discipline, people who engaging in news extortionists are both harmful to people and to themselves, and also destroy society and corrupt the atmosphere, so it is extremely damaging." [6] For governance countermeasures, many researchers provide suggestions from the aspects of improving the legal system, regulating the behavior of practitioners, optimizing media system restructuring, and media classification management. These studies have certain significance for strengthening the governance of news rent-seeking, but they generally ignored the systematic review and analysis of the news rent-seeking governance policy.

This paper attempts to use the theory of discourse institutionalism to retrospect China's news rent-seeking governance policy in the past 40 years, analyzes the gains and losses, and puts forward strategies for the optimization of news rent-seeking governance policies. Discourse institutionalism is a new school in neo-institutionalism and it is a complement to rational choice institutionalism, historical institutionalism, and sociological institutionalism. Rational choice institutionalism emphasizes interest logic, historical institutionalism pays attention to structure and system practice, and sociological institutionalism emphasizes cultural norms. They are all good at interpreting the static process of institutional change, but 
"cannot handle the influence of culture, beliefs, ideas and other 'non-material components' on actor's perception, behavior, and institutional choices"[7]. "Discourse institutionalism" makes up for the inadequacy of these three new institutionalisms. Vivian A. Schmidt from The American University of Boston, took the lead in including it into neoinstitutionalism. In Schmidt's view, "The institutions understood by discourse institutionalism do not follow the structure of external rules, but are simultaneously internal to the structure and construction of the initiative". Institutional change is the discourse interaction process expressed by institutional actors in specific semantics.[8]. The theory of discourse institutionalism consists of four aspects: First, "concept" and "discourse" are two core concepts. The legalization process of the discourse interaction of actors (including individual and collective) to express their institutional ideas is the process of institutional change. Second, the discourse interaction formed by the conceptual expression is carried out in the concrete "meaning context". Or, the policy actors must seek the legality of their policy concepts in public spaces and social fields (including policy fields and political fields). Again, discourse interaction must follow the "association logic" and dialogue on a democratic and equal basis under the "democratic negotiation" principle. In the end, we must "treat the institutional changes with a more dynamic perspective". [9]

Discourse institutionalism constructs a model of democratic political institutional change through key elements such as concept, discourse, context, actors, and negotiation. The change of news rent-seeking governance policy involves the discourse interaction of many stakeholders such as the ruling party, government authorities, the media, and the public. The policy changes at each stage are closely related to the development level of the media industry, there form degree of the media system, and the policy orientation of domestic political economy and culture. Use discourse institutionalism to study the news rent-seeking governance policy has higher relevance. It can be seen not only the gains and losses in the governance of news rent-seeking, but also it is an innovative attempt for media policy research theory.

\section{THE CHANGE OF NEWS RENT-SEEKING GOVERNANCE POLICY}

News rent-seeking is not the target product of the reform of news media system. However, institutional loopholes in the reform have led to the problem of news rent-seeking. Therefore, the emergence, development, deterioration of news rent-seeking and the media reform are at the same time period. Taking the media system reform as the main timeline, the news rent-seeking governance can be divided into three stages: start, strengthen, and institutionalization.

\section{A. Start of News Rent-seeking Governance}

Eight news media such as the People's Daily put forward business appeals for "public institutions and enterprise management" in 1978. In April of the following year, the Ministry of Finance promulgated the "Implementation method of the newspaper's trial enterprise fund" clearly stipulating that newspapers are the Party's propaganda institution. However, it allows corporate management, which opened the prelude to China's news media reform. The Document No. 37 of the CPC Central Committee promulgated in 1983 defined the principle and model of "Enterprise management of institutional organization" in broadcasting and television, and expanded the media marketization to the field of broadcasting and television. This dual operation mode in media field was originally a trial of "gradual reform" to "cross the river by feeling the stones" in the early days of reform and opening up, but it has been deeply influenced and gradually evolved into a so-called "dual track" media system. The dual operation of the news media allowed the government to get rid of the property burden of "Expenses covered", but "the special political identity of Chinese media and the industry monopoly position, because the original party newspaper system did not have the system design for industry rent-seeking, so endogenous corruption was grow along with it". [10] In the 1980s, news rent-seeking patterns such as "group draft fee", "red envelopes" and "transport fees" continued to emerge. Some news media used news as commodity for "selling", and engaged in "commodity news" and "advertising news". One of the "Shaanxi Workers" reporters received a bribe of 10,000 yuan, and the editor-inchief of the "Hainan Daily" had a bad influence for corruption and reselling car incident.

The Central Government believes that "news agencies engage in 'advertising news' and a variety of 'sponsorships' that undermine the reputation of journalism and the principle of news truthfulness". [11] In April 1985, the State Administration for Industry and Commerce, the Ministry of Radio, Television, and the Ministry of Culture jointly issued the first policy document entitled "Notice on issues concerning the operation of newspapers, books, magazines, radio and television stations", it pointed out: "Some news units publish so-called 'news advertisements' for money which confused the boundary between news and advertisements", and required examination and approval in accordance with the "Provisional Regulations on Advertising Administration" (1982) and relevant advertisement regulations. It is required that "nonbusiness advertising business departments shall not operate or represent advertising business" and "prohibit solicitation of socalled 'news advertisements' in the name of journalists", and news units "don't charge for news release". This document does not specify "news rent-seeking", but rather regard it as non-standard advertising behavior. Therefore, there is no specific punishment measure.

In 1990, the State Administration for Industry and Commerce and the Press and Publication Administration jointly issued the "Several Regulations on Newspaper Advertisements, Periodical Publishing Company, and Publishing Company Containing Advertisements" and requested the media to "disable publication of paid news". It uses "paid news" to define News rent-seeking for the first time. In the same year, the Ministry of Radio, Film and Television promulgated the "Interim Provisions of the Ministry of Radio, Film, and Television on Strengthening the Management of Sponsorship Activities" and the "Regulations of the Ministry of Radio, Film, and Television on Strengthening the Construction of Clean Government and Correcting Unhealthy Trends in the Industry". It requires that all units under the 
Ministry of Broadcasting and Television should not engage in any form of paid news, or any form of advertisement news in order to normative advertising sponsorships, and it firstly proposed "Unit or individual who conduct news rent-seeking will be punished based on the "Provisional Regulations on Administrative Arrangements for Corruption and Bribery of Staff of State Administrative Authorities" and "The State Council punished for violating financial regulations". The description of news rent-seeking by competent authorities from "unregulated advertising behavior" to "paid news", which marked the change of government governance attitudes and measures, and the governance has started. However, at this stage, the party and the government gave the tolerance for trial and error to the media system reform, and because of financial budget considerations, the management of news rent-seeking was not strong and the policy was lagging behind.

\section{B. Strengthening News Rent-seeking Governance}

The 1990s was the key stage of the reform of China's media system, marketization, industrialization, group and scale all have the unprecedented development. In 1992, the State Council promulgated the "Decision on Accelerating the Development of the Third Industry" and designated the "broadcasting and television industry" as a "Third Industry" and the Central Committee of the Communist Party of China approved "Several important issues concerning the strengthening of socialist spiritual civilization" in the Sixth Plenum of the 14th National Party Congress in 1996. The resolution on the issue proposed that "reforming the cultural system is the fundamental way out for the prosperity and development of cultural undertakings". In 1998, the Ninth NPC congress made it clear that newspapers, periodicals, radio and television were self-supporting. In 2001, the CPC Central Committee issued the "Several Opinions on Deepening the Reform of News, Publication, Radio, Film and TV Industry", to make a layout for the group development of media, and a series of reform measures and strategic adjustments make the news media from the mixed "business unit enterprise management" to market-oriented corporate legal "selfmanagement, self-financing, self-accumulation, selfdevelopment".

In the process of in-depth marketization, while the media industry is prospering, the pressure of business is also increasing day by day. The balance between economic benefits and social benefits has undergone subtle changes, and "create income" has been placed in a prominent position by media operators. "Some news organizations have a one-sided understanding of income-creation activities and believe that paid news can be promoted when news organizations are encouraged to generate income. Therefore, paid news is flooded on the news media and is difficult to prohibit". Some news organizations even encourage news reporters to pull advertisements and sponsorships to help organization create income, and give reporters $10 \%$ or more "commission" [12]. For the "paid news" that was frenzied by the domestic news media at that time, overseas counterparts lamented that this was "the practice of taking news to exchange for money like pork". [13] A group of old journalists hated it badly and wrote to the central government pointed out that "the news industry is sliding toward the mud plunging of 'money worship"' and called for the eradication of paid news as a poisonous snake.[14] What is even more frightening is that the flood of news rent-seeking activities such as paid news during this period has had a strong impact on economic order, government management, and public opinion guidance. For example, in the case of Wu Xinyong about "Xiang Zhong Ming Ji" and in the case of "Fanshi Coalmine Mishap", the reporter was "paid to know nothing", and the case of "Chang Cheng Xuan Feng".

The party and government attach great importance and start with the news team's cleansing, and strengthen the governance of news rent-seeking. In 1993 and 1994, the Central Propaganda Department successively issued the "Notice on Strengthening the Professional Ethics Construction of News Corps and prohibiting "Paid News'" and the "Notice on Persisting in the Construction of Professional Ethics of the Press Team". Journalists abide by professional ethics, honest and self-disciplined, for those use interviews and reports to engage in "paid news" will be handled according to law. In 1995, the Ministry of Broadcasting and Television issued the "Regulations on Correcting Unfair Practices in the Industry and Prohibiting 'Paid News", for the first time to make it clear that people who conduct paid news will give "administrative sanction". In 1997, several departments such as the Central Propaganda Department jointly issued the "Regulations on the Prohibition of Paid News", which clearly stipulates that individuals who conduct paid news "if break the law then transfer them to the judiciary" and propose criminal punishment measures for the first time. The penalties imposed on journalists for "paid news" have continued to increase. This has played a certain amount of shock. The "carriage fee", "receive red envelopes" and "commission" over a period of time have subsided. However, the "discount" policy implementation and "changed" rent-seeking has laid a hidden danger for the next phase of news-seeking "upgrade".

\section{News Rent-Seeking Governance Mechanism}

On December 31, 2003, the General Office of the State Council promulgated the "Regulations on Transforming Operating Cultural Institutions into Enterprises in the Pilot Project of Cultural System Reform". The media industry is divided into two parts: public interest media and business media, and the propaganda business and operating business are respectively reformed. The original "dual system" of "single system dual operation" was transformed into "dual track operation" promoted by attribute classification. Business media organizations such as advertising, printing, and distribution were stripped from the business system and transformed into enterprises and formed into independent market subject based on the standard of modern enterprise and modern property rights, and journalism reserves institution system and continues to deepen the reform of internal labor, personnel, and distribution policies. There are two drawbacks to this model: First, the autonomy of operating media units is too large, and it is difficult for competent authorities to supervise; second, the news media almost monopolizes public opinion and discourse power, and is more likely to trigger corruption. It is precisely because of this that the news rentseeking has intensified at this stage, from individual piecemeal 
paid news, extortion, to media organization's rent-seeking, collective rent creation, and was created as a "business model" for profiteering, even became the capital for a private show off by some people.[15] Deterioration of news rent-seeking has seriously eroded the authority and credibility of the news media, and even affected the image of the party and the government, so it has to resolutely resolved by iron fists. The news rent-seeking governance of this period has the following characteristics.

1) Governance policies cover all aspects of news production: For journalists, the "Provisions on the Professional Ethics of Journalists and Editors of China Radio and TV Broadcasting", "Regulations on the Management of News Acquisitioning and Editing Personnel (Trial)", "Implementation Plan on the Management of Radio, Film, and Television News Acquisition and Distribution Personnel", "Administrative Measures on Press Certifications" and other 10 governance policies have been issued. They require news reporters and editors to "resolutely put an end to all kinds of paid news behaviors" and for those who violated the regulations take disciplinary actions, "revoke the news and editorial personnel's credentials" and criminal penalties. In response to the organizational news rent-seeking behavior, the "Administrative Measures for Press personnel of Newspaper station" stipulates that "The press station and its staff members shall not seek unfair advantage in the name of a news agency, press station, or journalist, and may not ask the interview object to subscribe newspapers, make advertisements, offer sponsorships, or engage business activities in the name of news report, may not conduct paid news, false reports, and may not engage in activities that violate the professional ethics of journalism", issued the " Notice on Further Improving Self-examination and Selfcorrection of Unfair Trade Behaviors in the Field of Publication and Distribution", and required "newspaper publishing units must not conduct business activities with unfair competition or conduct any form of paid news". In response to news content, in 2011, it issued the "Regulations on Strictly Preventing False News Reports" and it requires" strictly implementation of responsible editing policy for editorial review and the editor-in-chief responsible policy for press release, and the all links in the publication process adhere to the 'three reviews and three proofreads', and carefully verify the news sources and content of reports to ensure that news reports are true, objective and accurate". In terms of the business activities of newspapers and periodicals, the "Notice of Prohibiting Newspapers and Periodicals from Apportioning Distributions" was issued in 2011, and personnel and distributors of editors are "forbidden to mix posts with issuer", "strictly forbid to assign the publishing take of newspaper to editorial staff", "newspaper reporters are strictly prohibited from publishing newspapers and periodicals", all forms of kickbacks are strictly forbid, "It is forbidden to use news extortion, paid news, and other illegal means to issue newspapers and periodicals".
2) The integration of governance forces and coordinated attacks: For a long time, the regulatory structure of "Nine dragons control one water" for news media has been fully criticized, the number of functional departments involved in management is too big and the functions are mixed, the responsibilities are unclear. In 2005, the Central Propaganda Department successively promulgated the "Opinions on Further Strengthening and Improving Public Opinion Supervision Work" and the "Implementation Measures for Strengthening and Improving Public Opinion Supervision Work", take the "public opinion supervision" as the main line to organically integrate the governance policies covering all aspects of news production, building a "defense network" to defense rent-seeking. In 2013, the General Administration of Press and Publication and the SARFT merged to establish the "General Administration of Press, Publication, Radio, Film and Television". In 2018, the news of "Summarization of the Press, Publication, Radio, and TV" were merged into the Central Propaganda Department, and the management functions of news and propaganda were continuously concentrated and optimized. The adjustment of the functions of party and government agencies has strengthened the synergy ability of news rent-seeking governance. In 2013 and 2014, the Central Propaganda Department and other departments jointly launched the "Special Action Against Blackmail and Fake News" to investigate and punish a group of news blackmail cases such as the "Shopping Guide", "China Special Issue", "China Economic Times" and 21st Century media companies. It was a sensation. The joint advancement of collaborative governance and special operations has made the problem of rent-seeking significantly improved.

\section{DISCOURSE INSTITUTIONALISM REFLECTION ON THE \\ CHANGE OF NEWS RENT-SEEKING GOVERNANCE POLICY}

The policy changes of discourse institutionalism mainly inspect the discourse interactions among policy subjects within a certain field. The key point is to clarify the support alliance and opposition alliance in policy changes. On one hand, it is necessary to clarify the differences between support alliances and opposition alliance so as to analyze the driving force of policy changes; On the other hand, we must observe the exchange of ideas and discourse between different subjects, and how to move from disagreements to consensus, and then select the preferred collective actions that meet the public concept. The ideas of multi-subjects such as government, experts, and the public have exerted an important influence on the survival and adjustment of the news rent-seeking governance policy. Although the government's orientation toward news media includes news propaganda, public opinion guidance, economic benefits, and industrial development, but maintaining the ideological stability and "maintaining and consolidating the ruling position and improving the ruling ability" are the core. The reform of the news media must, on one hand, reduce the financial burden on the government through the marketization of the media, reduce the cost of governance, and improve the ruling ability; On the other hand, 
it will strengthen the power of news media through industrialization, enhance the ability of news propaganda, and expand public opinion filed. In the early days of news media reform, the marketization brought a rapid rise of media industry, which not only reduced the dependence on government finances, but also greatly contributed to taxation and profitability, so the party and the government were happy to see it. Therefore, for the issue of early news rent-seeking, the competent authorities are more lenient in governance, only alert with "unregulated advertising behavior". In the 1990s, with the deterioration of news-seeking rents, the news media's credibility was becoming increasingly destructive. The Party and the government began to punish offend reporters. To reshape the image of the news media and ensure the guidance ability of public opinion by the supervision of journalists, after the new century, the "upgrading" of news rent-seeking problems not only caused the image of the news media to fall rapidly, but also damaged the image of the party and the government. The sound of social criticism has become higher and higher, the party and the government dealt with a batch of "news blackmail" incidents and rectified the news industry from all aspects.

In the process of news rent-seeking governance policy changes, the ability of experts and the public to express concepts and discourse has continued to increase along with the democratization and popularization of new media. In the $80 \mathrm{~s}$ and 90 s of the 20th century, the general public lack of an opinion expression platform so that in the change of news rentseeking governance policy they do not have the position for discourse interaction. Only senior experts and overseas media used their resource advantages to criticize the issue of news rent-seeking in order to influence policy choices. For example, on April 23, 1993, "World Journalist" published a report entitled "The Mainland Reporter Makes Money", criticizing domestic news rent-seeking. In May 1993, ten senior members of the press, including Zhong Peizhang and Dai Bang, jointly signed a call to the Central Committee for rectification of news rent-seeking, promoting the Central Propaganda Department attaches great importance to the reorganization of the news team at this stage. The rapid development of online media in the late 1990s ushered in the era of "everyone held a microphone". The exposure, discussion, and criticism of a large number of news rent-seeking incidents by the general public resulted in a powerful public opinion atmosphere that is a power during policy change of news rent-seeking governance that must be considered. Experts and scholars in this period have increased their reflection and criticism of news rentseeking. The research on the sources, harms, and countermeasures of news rent-seeking in academic papers has also promoted government decision-making.

It is undeniable that there are still some problems that cannot be ignored in the change of news rent-seeking governance policies: First, the inequality of discourse status among policy subjects makes the formation of multiple participation and coordinated governance unsteady. For the sake of ideological security and safeguarding the ruling security, under the principle of "The party manages media", the decision-making power of the party and the government in the governance of news media cannot be challenged, and the participation level of public and expert in policy changes is limited. Without the full participation of the public and experts, the change of news rent-seeking governance policies often lags behind. Second, multi governance in the news media area has reduced policy performance. The Chinese government organization system is a criss-crossing bureaucracy network. Under the hierarchical and departmentalization, an administrative system consisting of a combination of "bars" and "blocks" has been formed. The news media management business is subdivided into several departments. Due to the regulatory gap between the functions of the various departments in charge and the lack of implementation of the policies, news rent-seeking has not stopped. Third, there are too many normative documents and the effectiveness of policies is insufficient. The competent authorities generally adopted the "dynamic" approach to managing newsrentseeking, and basically formed a governance path of "problemgovernance-problem--re-governance--particularly severespecial strike", so governance policies often take the form of notices, announcement, action plans, etc with obvious stages and fragmentation. The lack of effective dissemination of laws and regulations on news dissemination has seriously affected the construction of a long-term mechanism for news rentseeking governance.

\section{OPTIMIZED PATH OF NEWS RENT-SEEKING GOVERNANCE POLICY}

In recent years, the central and local governments have highly mobilized administrative resources and even national violence machine to continuous implement the "Special Action against the Information Extortion and False News" through close cooperation, the central government has steadfastly curbed the issue of news rent-seeking. However, for the long term, more scientific and sound policies must be constructed to promote the mechanism and long-term effectiveness of news rent-seeking governance. From the perspective of discourse institutionalism, the optimization of news rent-seeking governance policies include the following aspects.

\section{A. Establish a Multi-elemental Co-governance Structure and Introduce More Views from Outside the Government}

China's news media have been implementing top-down management for a long time. Each functional department has introduced policies, divided sections and divided management systems according to the government's administrative system and power distribution structure, which not only imposes high administrative costs but also has low administrative efficiency. The inextricable link between the government and the news media, as well as the government's dual appeals to the news media, are destined to be "both as referees and as athletes", causing repeated problems in the news rent-seeking problem. The formulation of governance policies must focus on the introduction of social perspectives represented by experts, the public and social groups, and establish a policy framework for multiple participation in governance. Social forces played an important role in the governance of news rent-seeking in western countries such as Britain and the United States. For example, the operation of American media is "market-based and administrative-assisted", the public and social groups can 
exert pressure on the Federal Communications Commission to investigate suspected news rent-seeking, and even revoke its licenses; The "News Council" mechanism in the UK was perfect, and the industry's power played a major role in regulating journalism. In 1997, the National Association of Journals of PRC promulgated the "Announcement on Establishing a System of Journalists Accepting Social Supervision". It tried to establish a social supervision mechanism. However, due to the imperfect development of the domestic news industry associations and the lack of public enthusiasm for participating in social and public affairs, the result was not good. Since the Eighteenth National Congress, the Central Government has highly emphasized the comprehensive deepening of reforms, and called for the government to decentralize power, innovate administrative methods, and optimize the structure of government organizations in order to get rid of the "single-centered" government situation in the past and to build effective government, market, and social interaction mechanism to modernize governance systems and governance capabilities. In the light of the review reform, the governance of news rentseeking should take advantage of the situation to form a pattern of "government + society + market".

\section{B. Form a Multi-layered Coordination Policy System and Promote the Legalization of Policy Construction}

Most civil law countries in the world have issued the "News Law" or "Law on Mass Media", and news rent-seeking is regarded as an illegal crime. It faces not only massive fines, but also restrictions or prohibitions on continuing to engage in news activities. The majority of current news rent-seeking governance policies in China are regulatory documents of government departments. Most of them are based on administrative penalties, and their deterrent and long-term effectiveness are insufficient. Since the 1980s, academics and industry have been calling for the establishment of a news law. However, due to the complexity of legislation and the immature timing, it has never been introduced. Judging from the problems of news rent-seeking and other issues, the formulation of a complete industry law regulates news subjects and intricate interest relationships in news activities through the regulation of powers and obligations, can most effectively limit rent-seeking problems and further shape healthy media ecology.

\section{Adopting Diversified Policy Means to Improve the Science of Policy Implementation}

The news media is a "mouthpiece" and also is a "market subject" so it must shoulder the political mission of news propaganda and public opinion guidance, and it must also pursue profitable income generation and industrial development. The party and the government must both keep it "good" and "alive", insisting on social benefits and also paying attention to economic benefits. From a regulatory perspective, news rent-seeking governance should scientifically use social regulation and economic regulation. For the news rent-seeking that has already exist, we can use direct administrative means to take a strong strike to treat the symptoms as the first. For the prevention and long-term governance of news rent-seeking, we must pay attention to the use of economic means, improve the corporate governance structure, rationalize the relationship of property rights, optimize the industrial structure, expand the operating channel, and enhance the ability of legal profitability, so as to treat the symptoms. All in all, correctly handle the relationship between the government and the market, coordinate the government's "visible hand" and the market's "invisible hand", and create a policy environment conducive to the healthy development of news media.

\section{CONCLUSION}

Through the strong intervention of government administrative means, the issue of news rent-seeking in China has been temporarily suppressed in recent years. However, in the long run, news rent-seeking governance needs to ensure policy discourse democracy, form a discourse negotiation mechanism for multi-policy subjects, and continuously improve the quality of policy supply to build a reasonable institutional system, which is the strategy to solve the problem fundamentally.

\section{REFERENCES}

[1] Liang Jun, Gu Jiang. Game Analysis of News Rentseeking[J].ContemporaryCommunication,2009(5):26-29.

[2] Chen Xiang. The Expression Form of "News RentSeeking"[J].Press,2005(1):82-83.

[3] Zhang Zhian,Wu Jianming. Corruption in Media Operation: A Multilayered Interpretation from the Perspective of Institutions[J]. Media Watch,2004(4):18-19.

[4] Chen Weixing, Yu Guiquan.Power Devolution and Media Rent-seeking: A Comparative Institutional Analysis between China and Russia[J].International Press, 2010(7):50-55.

[5] Huang Hongzhen.The Changes of China's Media Regulation from the Perspective of News Corruption[J].Journal of Changsha University,2011(5):112-114.

[6] Zheng Baowei. On the Performance, Harm, Causes and Governance of News Extortion[J].Journalism Research Guide,2014(5):5.

[7] Xiao Xi. New School of New Institutionalism in Political Science:Discourse Institutionalism[J].Journal of Central China Normal University(Humanities and Social Sciences),2010(2):23-28.

[8] Vivian A. Schmidt, Translated by Ma Xuesong, Tian Yuqi.Discourse institutionalism: the explanatory power of ideas and discourse [J]. Foreign Theoretical Development. 2015(7):10-19.

[9] Shen Peiyan. Ideas, Discourse, and Institutional Changes: A Review of Discourse Institutionalism[J].Journal of Anhui Normal University(Humanities and Social Sciences),2017(5):323-329.

[10] Zhan Jiang. Analysis of Corruption System of Reporters Station[J].Youth Reporter, 2007(8):12

[11] Yi Ming. Implementing the spirit of Comrade Hu Yaobang's speech and improving the quality of the news team--Minutes of the national news business experience exchange meeting[J].News and Writing,1985(10):1-2.

[12] Zhou Qi. The positive and negative effects of income-generating activities in news organizations[J].News Line,1992(3):20-21.

[13] Gao Jinping. Analysis of Paid News in 20 Years[J].News Knowledge,2001(1):6-9.

[14] Wu Haimin. Warning Record of China News[J]. Chinese writer, 1995(3):91.

[15] $\mathrm{Hu}$ Shuli. The news rent-seeking is unforgivable [N]. Caixin Weekly, November 4, 2013. 